\title{
OFICINAS DE TRABALHO COMO INSTRUMENTO DE PESQUISA E APRENDIZADO
}

WORKSHOPS AS A TOOL OF RESEARCH AND LEARNING

\author{
Silvio Soares Macedo \\ Arquiteto, professor titular da FAUUSP e coordenador da pesquisa $O$ sistema de espaços livres e a \\ constituição da esfera pública contemporânea no Brasil. \\ e-mail: lapquapa@usp.br
}

\section{Fany Galender}

Arquiteta pela FAU-Mackenzie, com especialização na FAUUSP, e consultora da pesquisa $O$ sistema de espaços livres e a constituição da esfera pública contemporânea no Brasil.

e-mail:fgalender@uol.com.br

\section{Helena Degreas}

Arquiteta, mestre e doutora pela FAUUSP, pesquisadora QUAPÁ-SEL

e-mail: hdegreas@uol.com.br

\section{Denis Cossia}

Arquiteto pela FAUUSP, pesquisador TT-3 - Fapesp

e-mail: deniscossia@gmail.com

\section{Ana Cecília Arruda Campos}

Arquiteta e doutora pela FAUUSP, pesquisadora QUAPÁ-SEL

e-mail: arrudacampos@terra.com.br

\section{Rogério Akamine}

Arquiteto e mestre pela FAUUSP, doutor pela Osaka University e pesquisador QUAPÁ-SEL Pos-Doc.

Fapesp

e-mail: akaroger@hotmail.com

Faculdade de Arquitetura e Urbanismo da Universidade de São Paulo

QUAPÁ-SEL - Núcleo São Paulo

Rua do Lago, 876

São Paulo-SP - Cep.: 05508-080

Endereço eletrônico: quapaselsp@gmail.com

\section{RESUMO}

O presente texto procura apresentar as oficinas realizadas pela pesquisa $\bigcirc$ sistema de espaços livres e a constituição da esfera pública contemporânea no Brasil, ora em andamento no Laboratório da Paisagem/Projeto Quadro do Paisagismo no Brasil, da FAUUSP, com apoio da Fapesp.

Aborda-se esse processo de trabalho e as reflexões iniciais sobre sua contribuição para a pesquisa, tendo como base seis oficinas já realizadas a partir de 2007.

\section{Palavras-chave: Oficinas, pesquisa, aprendizado.}

\section{ABSTRACT}

The present paper intends to present the workshops that have been held by the research The system of open spaces and the constitution of the contemporary public life in Brazil, which has been carried out in 
the Laboratório da Paisagem/Quadro do Paisagismo no Brasil - FAUUSP and supported by Fapesp. It is about the work process and the initial reflections on their contributions for the research, regarding six workshops that have been already done since 2007.

\section{Key words: Workshops, researd, learning.}

A opção por realização de oficinas nas diferentes cidades envolvidas na rede de pesquisa $\bigcirc$ sistema de espaços livres e a constituição da esfera pública contemporânea no Brasil parte do envolvimento de parceiros na área acadêmica, na revisão de fundamentos e premissas voltados para a conceituação do sistema de espaços livres de cada cidade pesquisada, com vistas à formação de uma base de conhecimento da realidade brasileira, analisando seu processo de formação, sua diversidade e semelhanças.

Partindo da adaptação da expressão inglesa workshop, caracterizamos tais eventos pela realização de atividades de caráter intensivo, compartilhando experiências concretas, que vêm permitindo a reflexão sobre as diferentes hipóteses e pressupostos contidos nos objetivos da pesquisa. A primeira oficina foi realizada na cidade paulista de Sorocaba, em outubro de 2007. Aconteceram outras em Maceió, Vitória, Campinas, Belo Horizonte e Curitiba.

formato estabelecido tem sua origem na experiência do professor Silvio Soares Macedo no Projeto Orla, elaborado a partir de solicitação do Ministério do Meio Ambiente em 2002. Como assessor desse órgão, ele propôs a realização de discussões com agentes locais que, por conhecerem as características particulares de cada localidade, muitas vezes, empiricamente, a partir de uma vivência cotidiana, puderam fornecer subsídios para um diagnóstico-síntese de cada realidade.

Também a prática de "charretes", definida como uma atividade didática voltada para a imersão projetual, visando à elaboração de respostas para um dado problema em um curto espaço de tempo, foi um elemento inspirador para o segundo dia de atividades. As "charretes" têm sido bastante aplicadas como método de trabalho em diversas escolas de arquitetura de outros países, já sendo, inclusive, adotadas como processo de ensino, sobretudo no Programa de Pós-graduação da FAUUSP.

No primeiro dia, conta-se a participação dos agentes envolvidos na definição, implantação e gestão dos espaços livres urbanos, tanto no âmbito público como no privado. Secretarias estaduais e municipais, órgãos federais, empresas de grande porte com significativa participação no desenvolvimento da cidade, companhias de água e saneamento, empresas ligadas ao mercado imobiliário e de turismo, população organizada (ONGs, associações de moradores, etc.) são protagonistas, com a universidade, na participação das apresentações realizadas no primeiro dia das oficinas e nas discussões e proposições do dia posterior. A riqueza dessa troca de informações, posturas e intenções, que se encontra fragmentada em seus locais de origem, tem-se mostrado bastante eficaz, uma vez que aquelas se revelam e são partilhadas pelo grupo em sua totalidade.

A oficina permite a caracterização do espaço livre urbano daquele município e/ ou região metropolitana, partindo da discussão sobre as bases da constituição do sistema de espaços livres identificado, suas especificidades e particularidades, seus critérios de distribuição e sua articulação com o tecido urbano, diante das tendências 
do crescimento urbano, às características do suporte físico e à natureza do vínculo que estabelece com o usuário.

A dinâmica envolve, além da exposição de conhecimentos específicos, a análise e o diagnóstico preliminar, advindo dessa caracterização elaborada por atores com atuação efetiva naquela situação, contribuindo na identificação de conflitos e potencialidades que o contexto apresenta.

Paralelamente ao processo de realização das oficinas, iniciam-se os estudos sobre o papel da legislação local na constituição dos espaços livres urbanos públicos e privados, a revisão acerca da nomenclatura própria da área utilizada por técnicos, estudiosos e legisladores, sobretudo no âmbito público, provocando conflitos no entendimento mais aprofundado da questão dos espaços livres na constituição da paisagem urbana.

Três relatos são apresentados logo após a redação das Conclusões, de modo a apresentar nossa sistemática de trabalho. Foram selecionadas as oficinas de Maceió, Vitória e Belo Horizonte, devido à suas particularidades regionais; suas dinâmicas específicas, oriundas das características dos participantes e sua evolução urbana.

\section{CONCLUSÕES}

O número de oficinas realizadas já nos permite iniciar a reflexão para o desenvolvimento de uma metodologia de avaliação da lógica dos diferentes sistemas de espaços livres urbanos, identificando pontos comuns e pontos específicos de cada situação urbana. Tal trabalho, ora em andamento pela equipe de coordenação nacional, é também acompanhado pelo trabalho de simulação gráfica da legislação específica dos municípios selecionados e pela elaboração de mapas de verticalização $\mathrm{x}$ espaços livres, sistema viário, uso e ocupação do solo, confronto com dados censitários das áreas em estudo, entre outros.

Como aspectos positivos, identificamos:

- A observância em planos diretores de princípios ambientalistas que influenciam a geração de espaços livres de portes diversos, associados à conservação de recursos naturais;

- a instituição das áreas de proteção ambiental urbanas como um fato a ser concretizado;

- o aumento das ações que envolvem a conservação de recursos ambientais, como manguezais e florestas urbanas;

- produção crescente de novos parques e orlas tratadas;

- a constituição de uma série de parques lineares;

- a consolidação da praça esportiva;

- proteção efetiva de áreas de várzea e corpos d'água;

- a efetivação da ciclovia como um canal de trânsito, mas também como um espaço de recreação da população;

- a criação dos primeiros sistemas integrados de parques;

- investimentos públicos de porte para a recuperação de áreas reservadas para a construção de parques e invadidas pela população, em especial aquelas situadas 
às margens de rios;

- valorização crescente nos códigos de ao menos parte das cidades sobre o papel do espaço livre no âmbito privado, com o conseqüente aumento de prescrições para concretizar sua existência.

Apesar de esses itens todos refletirem um aumento da importância dada pelo poder público aos espaços livres, ainda são muitos os fatores que impedem o atendimento das demandas urbanas para tal tipo de espaços.

A título de constatação geral inicial, podemos afirmar que as variações que sofrem as estruturas administrativas locais concernentes à produção e gestão dos espaços livres urbanos na cidade brasileira, é evidente a sobreposição de ações em relação à sua implantação, desenho e manutenção, além da descontinuidade em sua linha de planejamento, dada a constante interrupção das atividades e os redirecionamentos políticos, nem sempre tecnicamente bem amparados.

Constatamos ainda:

- Falta crônica de recursos para a implementação de novos logradouros;

- falta de recursos e equipes de manutenção e gestão;

- dispersão de responsabilidades, recursos e ações entre departamentos e secretarias municipais responsáveis pela produção e gestão de espaços livres públicos;

- políticas equivocadas a respeito, as quais, de fato, não atendem às demandas do todo da população;

- despreparo de equipes técnicas tanto para o planejamento como para o projeto de espaços públicos. Existe, de fato, uma confusão de prioridades para o atendimento das demandas, que, em grande parte, dependem de oportunidades e programas políticos para sua implementação;

- ausência real de entendimento técnico e político de tratar-se os espaços livres públicos, em especial aqueles dedicados à conservação e recreação como partes de um sistema e seu alto interesse por parte da população.

Concomitantemente à realização de novas oficinas, estamos iniciando a etapa de balanço das já realizadas em parceria com as equipes locais que, após cada evento, passam a articular-se efetivamente como um núcleo local, dando prosseguimento ao trabalho proposto. Ainda percebemos a necessidade de estreitamento desses vínculos, por meio da criação de instrumentos que dêem continuidade ao processo iniciado, produzindo desdobramentos concretos, com a troca de produtos entre a pesquisa de âmbito local e a de escala nacional.

Os resultados das oficinas são heterogêneos, em parte devido às dificuldades locais de envolvimento dos parceiros, infra-estrutura de apoio das instituições de ensino, dificuldades internas de formação dos núcleos (estabelecimento de prioridades na eleição de temas pelos departamentos, lentidão de fornecimento de subvenção das agências de fomento a pesquisas locais, etc.).

Podemos destacar o caso de Sorocaba, que, apesar do envolvimento com uma universidade local (UNIP), a atuação conjunta está ocorrendo mais solidamente por meio do Núcleo de Planejamento da Prefeitura Municipal (Nuplan), tendo sido celebrado 
um Termo de Cooperação Técnica entre a FAUUSP e a prefeitura de Sorocaba, após a realização da oficina. Os trabalhos acabam de ser iniciados e estão voltados para a elaboração de um plano diretor para os espaços livres daquela cidade.

As oficinas: Belo Horizonte, Vítória e Maceió

Os textos a seguir foram extraídos do relatório encaminhado à Fapesp em 2007 e adaptados à apresentação do presente artigo.

\section{OFICINA DE TRABALHO EM BELO HORIZONTE-MG}

Dias 03 e 06 de junho de 2008

Local: Escola de Arquitetura e Urbanismo da Universidade Federal de Minas Gerais (EAU-UFMG)

Participantes do QUAPÁ-SEL- Núcleo São Paulo: os professores doutores Eugênio Fernandes Queiroga e Helena N. Degreas e Vanderli Custódio; arquitetos Fany Galender e Denis Cossia; e o graduando Alexander Villalon.

Dia destinado à realização de visitas técnicas aéreas e terrestres que objetivam o reconhecimento da cidade de Belo Horizonte, possibilitando a observação e registro em imagens dos diferentes tecidos urbanos e das tipologias dos espaços livres urbanos, significativos das principais localidades que compõem sua região metropolitana.

Os percursos foram realizados em circuitos previamente estabelecidos com os parceiros locais, que participaram tanto do sobrevôo como das visitas terrestres. A equipe por terra visitou as áreas planejadas, diversas praças, destacando-se o Parque Municipal e a Barragem de Santa Luzia. Esses locais foram observados e descritos por meio de fotos, texto e a relação de equipamentos, manutenção e uso social dos espaços.

Abertura: recepção e apresentação dos convidados e participantes no auditório da EAU-UFMG

Prof. Dr. Eustáquio (diretor da EAUU-FMG); professores doutores Marieta Cardoso Maciel (EAUU-FMG), Stael Alvarenga Pereira Costa (EAUU-FMG), Lúcia Capanema Álvares (EAUU-FMG) e Maria Cristina Villefort Teixeira (EAUU-FMG).

\section{Apresentação 1}

\section{Os sistemas de espaços livres e a constituição da esfera pública} contemporânea no Brasil: Um processo de investigação nacional

Prof. doutor Eugênio Queiroga/FAUUSP - coord. nacional da Pesquisa QUAPÁSEL e professora Fanny Galender/FAUUSP - grupo da Pesquisa QUAPÁ-SEL - Núcleo São Paulo

Foram apresentados os objetivos da Pesquisa QUAPÁ-SEL Nacional, destacando sua história, objetivos e os procedimentos de trabalho adotados na realização das oficinas com alguns resultados parciais. 
A abordagem dos espaços livres de edificação enfatizou a visão sistêmica e a relação dos espaços privados e públicos, descrevendo morfológica, cultural, ambiental e funcionalmente vários exemplos advindos das diversas oficinas já realizadas. Dentre os objetivos, os palestrantes destacaram que a pesquisa em rede objetiva investigar: - SEL das cidades brasileiras; o SEL como representante de uma cultura urbana, o vínculo entre espaços livres e vida pública, a estruturação urbana das cidades brasileiras, as iniciativas da população, instituições e empresas na qualificação e requalificação dos espaços livres nas cidades brasileiras; os valores dominantes sobre os ELS, a contribuição dos espaços livres para a constituição de princípios públicos gerais de políticas públicas em toda a realidade observada, esperando-se construir um referencial teórico que permita a interpretação e divulgação dos estudos.

\section{Apresentação 2}

\section{O ambiente e a gestão de espaços públicos em Belo Horizonte:} Áreas verdes e arborização

Arquiteta Márcia Mourão Parreira do Amaral - gerente da Gestão Ambiental da Secretaria Municipal Adjunta de Meio Ambiente (SMAMA).

A palestrante inicia sua fala a partir da descrição do zoneamento realizado em $\mathrm{BH}$ e o papel do poder público na fiscalização, gestão e manutenção dos espaços públicos, descrevendo os resultados do trabalho com a população na decisão sobre uso e preservação dessas áreas.

Das políticas em andamento, a palestrante destacou cinco programas: 1) conhecimento das 701 praças e dos 57 parques da cidade; 2) criação de um banco de dados de áreas verdes, identificando as abandonadas, conhecimento do entorno e definição de funções; 3) viabilização da troca de uso de áreas públicas; 4) atendimento aos pedidos locais como áreas para caminhada e pista de skate; 5) arborização de logradouros públicos. Destaca e descreve o Programa BH Verde, no qual se trabalha com a permuta de áreas entre secretarias.

\section{Apresentação 3}

\section{Programa de Recuperação Ambiental de $\mathrm{BH}$}

Janice Shimid de Novaes (engenheira de obras da Sudecap - Drenurb)

A engenheira descreve algumas características físicas e sociais da região metropolitana de $\mathrm{BH}$, destacando o tratamento da hidrografia urbana por meio do Plano 
Diretor de Drenagem (Drenubs), parte integrante do plano diretor municipal. Descreve o método de trabalho; o projeto (terceirizado) destaca as principais obras e dedica o sucesso da intervenção à continuidade política municipal. As intervenções contam com aporte financeiro do BID.

\section{Apresentação 4}

Espaços públicos nos assentamentos existentes (PBH): Programa Vila Viva

Arquiteta Maria Cristina Fonseca de Magalhães

Atuação em áreas de grande fragilidade social, com o objetivo de recuperar e integrar assentamento, adotando o conceito "intervenção estruturante", e estabelecendo ações por eixos: Eixo Urbanístico Ambiental, Eixo Sistemático Habitacional e Eixo Regularização Fundiária. Cita o Caso do Aglomerado da Serra, descrevendo o plano, o processo de projeto e construção, destacando a participação dos moradores na gestão dos espaços semipúblicos e o excelente relacionamento da comunidade com o poder público. Caso da Flor de Maio: área de risco na qual se realizou tratamento de uma encosta. Caso Núcleo Habitacional São João: local de efetuação de tratamento de espaços livres públicos gerados nos conjuntos habitacionais, com participação da população no plantio de mudas e manutenção e organização de um conselho gestor colegiado: poder publico e comunidade (exigência do licenciamento).

\section{Apresentação 5}

Movimentos populares/Organizações sociais. Associações de moradores Senhora Edna Barbosa (AMA Cidadania)

A palestrante descreve sua experiência na Vila Novo Ouro Preto (Pampulha), expondo a situação dos córregos repletos de lixo e encostas perigosas, associando a atuação conjunta ao poder público. Ela mostra que a atuação conjunta evita depredações propositais do povo e declara a todos os presentes que o poder emana daquela e, na qualidade de pagantes de impostos, os moradores da favela precisam participar e reivindicar. Exemplifica que a associação evita o uso de conceitos como elitismo e paternalismo, exemplificando com o relato de uma antiga área de lixão a céu aberto transformada em parque linear, sonho da comunidade. A operacionalização, tanto do projeto quanto da organização da comunidade se deve à orientação de alunos e 
professores da Escola de Arquitetura da UFMG. Ainda de acordo com a palestrante, - Movimento de Cidadania Pelas Águas lutou e conseguiu só umas pedrinhas, mas o povo é governo e, como eles moravam sobre as nascentes com lixo e esgoto também por eles produzidos, eles mesmos precisavam se organizar e reivindicar.

\section{Apresentação 6}

\section{Pró-civitas}

\section{Senhora Juliana Renault}

Representante de dois bairros também na Pampulha, trabalha com várias associações de bairros (Bandeirantes, Pampulha e outras) e considera que, na cidade, os problemas são muito parecidos, seja na favela, seja nas áreas ricas. Cita vários exemplos de conflitos vinculados a comportamentos públicos e necessidades da população, enfatizando que a falta de capacidade de gestão e manutenção pública do espaço é um dos principais motivos desses conflitos.

Cita cinco reivindicações da associação, por ela presidida, quanto à manutenção, reformas e projetos de espaços livres públicos. Reitera que as demandas levadas ao poder público não são atendidas, cabendo à população reivindicar e fazer-se ouvir.

\section{Apresentação 7}

\section{CREA - Sindicato dos Arquitetos/Instituição de ensino}

Arquiteto Eduardo Fajardo Soares (Sinarq)

palestrante discorreu sobre a atuação do sindicato nas questões vinculadas aos conflitos entre interesses públicos e poder público. Dentre os vários conflitos exemplificados, destacaram-se a praça da Liberdade e arredores, o Centro de Referência do Professor, entre outros.

\section{Debate}

debate versou sobre vários assuntos, destacando-se o Projeto Vila Viva e as alterações de residências para apartamentos, dimensões mínimas e seu custo; sobre forma de cálculo do Sistema Nacional de Unidades de Conservação - SNUC - nos parques implantados.

\section{Apresentação 8}

\section{Observatório de Conflitos Urbanos de $B H$}


Profa. Dra. Lúcia Capanema Álvares - Coordenação Local (EAU-UFMG)

Para a viabilização do início da proposta de pesquisa SEL-BH optou-se pelo uso de recursos da disciplina de Paisagismo da EAU-FMG (e, posteriormente, uma disciplina da área de Turismo), cuja área de intervenção foi uma favela, contando com a colaboração da URBEL e dos moradores para a elaboração do projeto de paisagismo. Formalizado o vínculo com o Observatório de Conflitos Urbanos do IPPUR do Rio de Janeiro, constituiu-se o Núcleo SEL-BH, o qual passou a monitorar e mapear todo tipo de manifestações coletivas ocorridas nos espaços públicos, repercutidas nas principais mídias impressas e televisivas registradas nos conselhos municipais.

\section{Apresentação 9}

Trabalhos da UFMG. TGI sob orientação da professora Marieta Cardoso Maciel da Coordenação Local (EAU-UFMG)

\section{Aline Ramos}

TFG: Intervenção Parque Albergue Castello Branco - o trabalho apresenta o levantamento, análise e diagnóstico da região escolhida para intervenção, situada junto do Elevado Castello Branco. É proposta a implantação de um parque linear e um albergue para a população moradora da área.

Aline Betat

TFG: Proposta de implantação de um parque urbano em Lagoa Santa-MG, com a apresentação de um breve histórico e características da cidade. A gênese do projeto veio da participação da aluna nas reuniões do plano diretor da cidade, quando percebeu as demandas da população local.

3으 dia: 05.06.2008

A oficina

A oficina de $\mathrm{BH}$ aconteceu na EAU-UFMG e contou com a participação de 19 integrantes vinculados à área de graduação e alguns professores predominantemente vinculados à escola anfitriã.

Foram organizadas duas equipes compostas por professores e alunos. Diferentemente das demais oficinas, os trabalhos foram iniciados com a discussão e fechamento das apresentações dos palestrantes ocorridas no dia anterior.

Os temas abordados foram:

Equipe 1

- Espaços livres privados

- Padrões de tecidos urbanos

- Legislação, planos e diretrizes do poder público

- Mercado imobiliário e tendências 


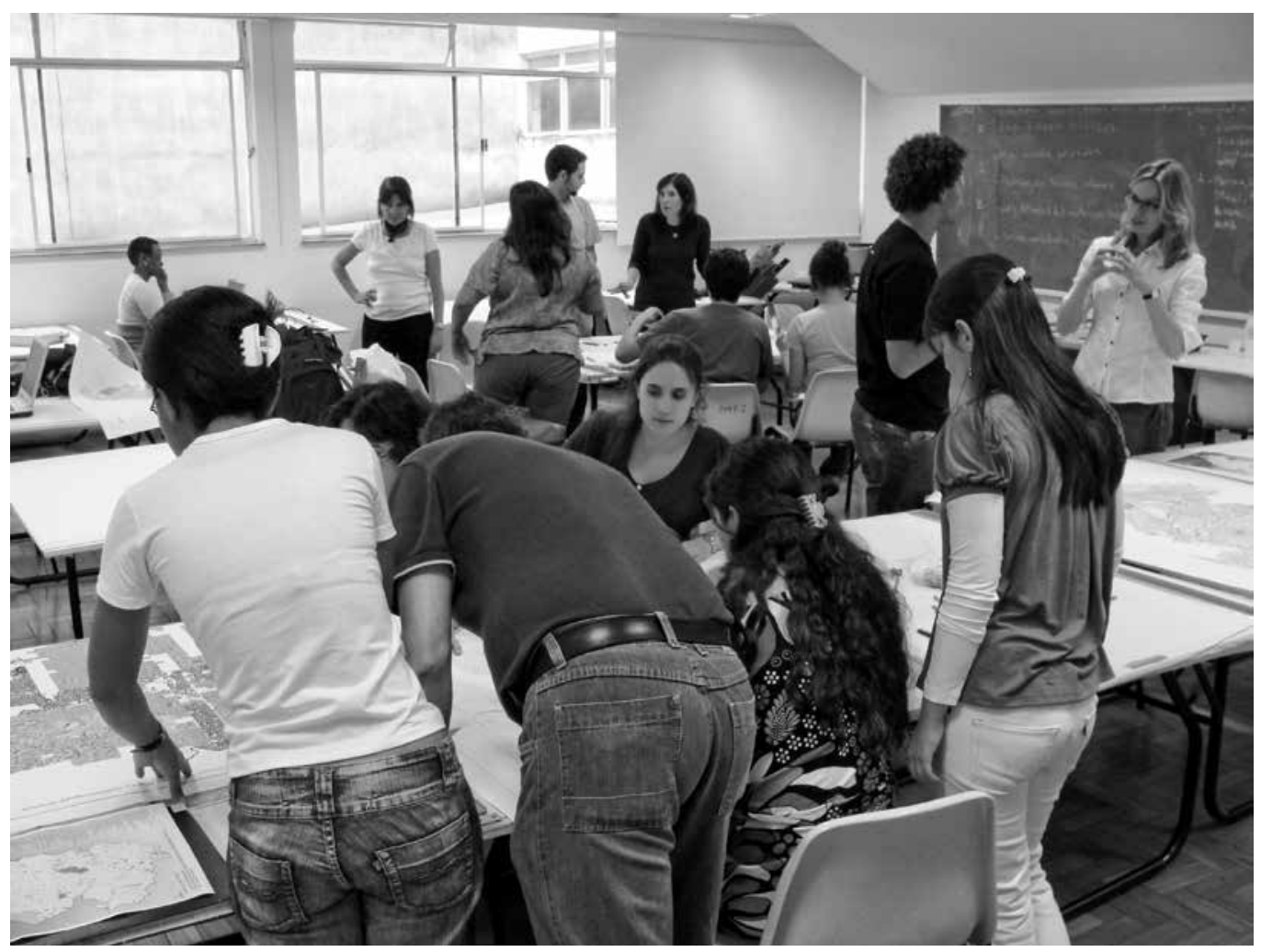

Terceiro dia de trabalho da oficina de Belo Horizonte

- Estruturas lineares (ferrovias, rodovias, vias arteriais, hidrografia)

\section{Equipe 2}

- Estruturas lineares (ferrovias, rodovias, vias arteriais, hidrografia)

- Espaços livres públicos

- Legislação, planos e diretrizes do poder público

\section{Oficina de trabalho em Maceió-AL}

Dias 02, 03 e 04 de dezembro de 2007

Local: Universidade Federal de Alagoas (UFAL)

Participantes do Núcleo QUAPÁ-SEL São Paulo: Os professores doutores Sílvio Soares Macedo (FAUUSP), responsável geral pelo Projeto QUAPÁ-SEL, Jonathas Magalhães Pereira da Silva (Universidade Anhembi-Morumbi), Vanderli Custódio (IEB-USP - Geografia), arquiteto Denis Cossia (QUAPÁ-FAUUSP) e Gustavo Meirelles (discente FAUUSP).

Núcleo Maceió: coordenação do Prof. Dr. Geraldo Majela Gaudêncio (FAU-UFAL).

02.12.2007

Um dia antes do início do evento, o professor Sílvio Macedo, Denis e Gustavo 
realizaram um sobrevôo sobre a cidade de Maceió, no intuito de obter fotos aéreas atualizadas sobre as quais poderíamos trabalhar nos dias subseqüentes. Elas compõem um banco de imagens do Projeto QUAPÁ-SEL nacional, bem como já estão disponibilizadas para o Núcleo Maceió e todos os participantes do evento. O grupo de São Paulo, assessorado pelo Prof. Dr. Geraldo Majela, realizou reconhecimento da cidade, percorrendo-a de carro: as áreas de favela, as industriais, as de casario tradicional, o centro comercial, histórico, os mirantes e a orla marítima.

\subsubsection{7}

No primeiro dia, reservado a exposições sobre a cidade, a oficina contou com cerca de 30 pessoas entre técnicos e acadêmicos, em sua maioria arquitetos de formação, mas também geólogos e geógrafos, provenientes de órgãos públicos municipais, estaduais e mesmo federais. Cabe destacar os participantes da Secretaria Municipal de Planejamento de Maceió, do Patrimônio da União (Marinha), do lbama, das prefeituras de Arapiraca e Palmeira dos Índios, do órgão de Unidades de Conservação do Estado de Alagoas, muitos pós-graduandos de mestrado e doutorado, bem como professores do Grupo de Estudos de Morfologia dos Espaços Públicos, da Faculdade de Arquitetura, coordenado pelo Prof. Dr. Geraldo Majela.

Pela manhã, o professor Sílvio Macedo apresentou os objetivos do Projeto QUAPÁSEL Nacional e da oficina. O professor Majela expôs como se deu a organização e engajamento do Núcleo Maceió, no projeto, e apresentou cronograma dos trabalhos.

Desse dia destacam-se as exposições do representante do Patrimônio da União (Terrenos da Marinha), por conta do desconhecimento (técnicos e acadêmicos) sobre os objetivos e formas de atuação do órgão; e da representante da prefeitura, a qual detalhou o plano diretor.

Dessas exposições registramos que o território de Maceió é de $513,55 \mathrm{~km}^{2}$, sendo 191,79 km² de área urbana, ou seja, $37 \%$. O restante é constituído por três unidades de conservação em torno da área urbana, área rural composta por grandes propriedades de cultivo de cana-de-açúcar - cultura que caracteriza o estado de Alagoas. Os 800 mil habitantes se dividem entre o tabuleiro, constituído por um extenso conjunto de grotas, alguns núcleos ao longo dos $40 \mathrm{~km}$ de orla marítima e a lagoa Mundaú. Conjuntos habitacionais construídos pelo poder público constam aqui e ali na paisagem urbana, sobretudo do tabuleiro; as favelas, destacando a denominada Sururu de Capote, encontram-se ao longo do trecho urbano da lagoa Mundaú e apresentam muita precariedade nas construções de madeira e plástico. Moradias precárias também são encontradas ao longo do córrego Reginaldo, o qual nasce no tabuleiro e deságua na orla, com o nome de Salgadinho. Na orla sul está a grande indústria química Brasken, - histórico e reformado bairro Jaraguá, o porto de Maceió, as praias de Pajuçara e Ponta Verde, com adensamento vertical destinado à moradia das classes altas e aos hotéis para os turistas, e quiosques de praia com serviços de alimentação. Na orla norte há moradias horizontais de classes médias e altas e, no extremo norte, há pouca ocupação, mas projetos de construção de resorts e outros tipos de infra-estrutura de 
grande porte para fins turísticos (Anexo 2).

Ressalta-se a importância de projetos federais diversos e dos serviços públicos, em geral, bem como a atividade de construção civil, na oferta de empregos urbanos. A cultura da cana, mesmo com colheita manual, não utiliza a mão-de-obra urbana excedente, pois os donos de usinas e plantações preferem contratar os sertanejos e não os desempregados da cidade, pois aqueles cortam mais toneladas/cana por dia.

A proposta básica do Plano Diretor de Maceió, no que diz respeito aos espaços livres, é a descentralização das áreas de lazer, de forma a evitar o deslocamento da população para o centro da cidade e orla em busca de lazer e recreação. Priorizam-se calçadões, praças, ciclovias, mirantes, corredores culturais e similares. A cidade não tem tradição no uso de parques.

No período da tarde foram apresentados trabalhos de investigação de mestrado e doutorado, em andamento e concluídos, sobre diversos aspectos do tema "Sistema de espaços livres urbanos", orientados pelo Prof. Dr. Geraldo Majela. Alguns mais específicos, outros nem tanto, mas todos de interesse. Destacou-se o trabalho em andamento de Nelcy M. Santos (Deha-Ufal) sobre Os campos de pelada e a dinâmica do sistema de espaços livres em Maceió. Segundo a autora, existiriam mais de 480 campos de pelada em Maceió; e o trabalho das professoras Regina Lins e Veronica Robalinho (Nest-Ufal), sobre Pesquisa sobre vazios urbanos em Maceió, com elaborado nível teórico.

Tanto no vespertino quanto no período matutino, os debates foram "acalorados" e muitas dúvidas entre acadêmicos e técnicos foram esclarecidas. Sentimos a ausência de representantes de movimentos sociais e Organizações Não-Governamentais (ONGs) interessados em discutir questões urbanas relacionadas ao tema.

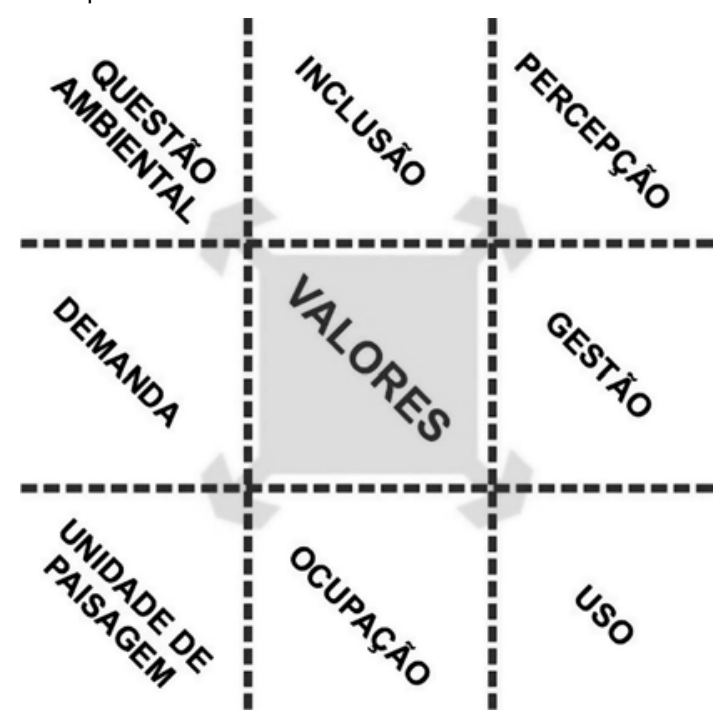

que se pôde observar/concluir no primeiro dia foi a preocupação recorrente sobre como desenvolver o turismo em Maceió, sobretudo na orla marítima, sem causar problemas ambientais.

No segundo dia, reservado para os trabalhos em grupo sobre carta do município, 
o professor Jonathas Magalhães elaborou a síntese das exposições do dia anterior, na forma do esquema abaixo:

Ou seja, a Percepção Individual das diferentes Unidades de Paisagem é construída por Valores contraditórios de diferentes grupos sociais. Esses Valores irão definir o Uso e Ocupação do território, na medida em que os diferentes grupos são incluídos na Discussão Ambiental. A maior tensão operacional, do Sistema de Áreas Livres, é revelada pela Demanda Social de Espaços Livres de Edificação, de modo a promover a qualidade da área urbanizada. Acredita-se que um bom encaminhamento dessas questões reside na Inclusão de diferentes grupos sociais, estabelecendo-se as prioridades e definindo as formas de Não-ocupação dessas áreas e sua forma de Gestão.

As apresentações feitas até aquele momento mencionaram, de certa forma, os pontos explicitados pelo gráfico; entretanto, percebeu-se que as discussões realizadas no dia anterior não conseguiram promover uma visão dos diversos aspectos necessários para a avaliação ou estudo de um sistema de espaços livres. A intenção, ao se apresentar o gráfico acima, foi resgatar as diversas falas, procurando estabelecer as conexões existentes e sugerir uma complementaridade.

Nesse dia o número de participantes da área técnica foi menor, por conta das demandas da função ou cargo de cada um; mesmo assim, pela manhã, foi possível formar cinco grupos mistos (técnicos e acadêmicos), com quatro ou cinco pessoas e alocá-los para a discussão dos seguintes temas:

- Paisagens, ecossistemas e conservação;

- ações turísticas;

- mercado imobiliário: vetores de expansão e habitação;

- praças e parques: sistema de espaços livres públicos;

- tipos de tecido urbano: sistema de espaços livres privados.

A proposta visava à elaboração de um diagnóstico temático sobre Maceió, preenchendo os seguintes itens: a) caracterização; b) conflitos; e c) potenciais.

Sobre uma carta colorida de 1:35.000 os grupos trabalharam até às 13 horas. No meio da tarde chegaram dois representantes do Movimento Terra e Liberdade (MTL), defensor da propriedade da terra urbana e rural para os pobres. Na apresentação informaram a existência de 4.500 famílias sem terra em Alagoas, expulsas pela concentração fundiária em prol da monocultura canavieira. Na cidade, muitas dessas famílias não têm moradia nem emprego. Nesse sentido, o movimento luta pela participação nos programas públicos destinados à construção de moradias urbanas e à criação de áreas e galpões cooperativos, em que possa produzir e comerciar hortifrutigranjeiros e artesanato. Por conta de compromissos anteriormente assumidos pelos expositores, não houve debate.

Findos os trabalhos com a carta, cada grupo apresentou a síntese temática e o professor Sílvio Macedo elaborou a síntese geral sobre Maceió: a) a cidade possui muitos espaços livres urbanos por todos os tipos de tecido; b) há um excesso de planos para a orla, mas quase nada para o restante da cidade; c) falta um projeto de cidade. $\bigcirc$ 
professor Jonathas Magalhães ressaltou a importância da atuação política do arquiteto para a inclusão de demandas populares nos projetos públicos. A professora Vanderli Custódio alertou para o fato de, metodologicamente, em geografia urbana, não se estudar uma cidade sem considerar-se o contexto regional, ou seja, a rede urbana a qual ela pertence e o contexto nacional, o do processo geral de urbanização, como parecia estar sendo feito em Maceió. Somente quando indagados os grupos mencionaram aspectos da relação de Maceió com sua região metropolitana. Ressaltou que a cidade é constituída, em sua maioria, por pessoas pobres e suas demandas precisam ser consideradas nos projetos urbanos concebidos pelos órgãos públicos.

Como balanço geral da oficina, o Núcleo São Paulo concluiu:

1) Guardadas as peculiaridades históricas, geográficas e paisagísticas, o caso de Maceió é semelhante ao de Sorocaba-SP, no sentido de a cidade ser possuidora de um "estoque" significativo de espaços livres urbanos;

2) a oficina foi muito bem organizada;

3) o trabalho em grupo por temas, sobre carta da cidade inteira, foi muito mais proveitoso para o conhecimento da realidade urbana do município do que cada grupo tratar de todos os temas sobre cartas regionais da cidade;

4) o conhecimento do Brasil, por parte dos pesquisadores do Eixo Sul-Sudeste do país, requer deslocamento, requer pesquisas in loco;

5) os ganhos, no sentido das discussões realizadas (o encontro entre acadêmicos, técnicos, ONGs, outros representantes da sociedade civil e setores econômicos com interesses urbanos) e dos materiais produzidos (fotos aéreas) são recíprocos: tanto para os núcleos QUAPÁ-SEL locais como para a coordenação nacional. 


\section{PROGRAMA OFICINA MACEIÓ}

\section{Rede Nacional de Pesquisas QUAPÁ-SEL}

\section{Sistema de Espaços Livres Urbanos e a Constituição da Esfera Pública Contemporânea no Brasil}

Oficina Maceió: 3-4.12.2007

Local: Mestrado DEHA/Fau-Ufal - Campus A. C. Simões

Universidade Federal de Alagoas

Universidade de São Paulo

Faculdades de Arquitetura e Urbanismo

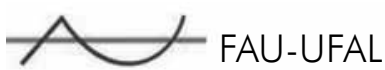

FAUUSP

Organização: Núcleo de Estudos de Morfologia

dos Espaços Públicos (MEP - FAU-UFAL)

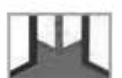

Participação do Núcleo Coordenador Nacional:

Laboratório da Paisagem (QUAPÁ-FAUUSP)

\begin{tabular}{|c|c|}
\hline $\begin{array}{l}3 \text { de dezembro } \\
\text { segunda-feira }\end{array}$ & Programa \\
\hline $8 \mathrm{~h} 30-9 \mathrm{~h} 00$ & Abertura e apresentação dos participantes e convidados \\
\hline $9 \mathrm{~h} 00-10 \mathrm{~h} 00$ & $\begin{array}{l}\text { Apresentação do projeto e da rede nacional de pesquisas } \\
\text { (QUAPÁ - FAUUSP) }\end{array}$ \\
\hline $10 h 00-10 h 20$ & Intervalo para o café \\
\hline $10 \mathrm{~h} 20-11 \mathrm{~h} 10$ & Gestão municipal dos espaços livres municipais (Prefeitura de Maceió*) \\
\hline $11 \mathrm{~h} 10-11 \mathrm{~h} 30$ & $\begin{array}{l}\text { Gestão das Unidades de Conservação Estaduais (IMA, CASAL, } \\
\text { polícia ambiental) }\end{array}$ \\
\hline $11 h 30-11 h 45$ & $\begin{array}{l}\text { Gestão das Unidades de Conservação Federais e Terrenos da } \\
\text { União (Ibama, SRPU) }\end{array}$ \\
\hline $11 \mathrm{~h} 45-12 \mathrm{~h} 00$ & Debates \\
\hline $12 \mathrm{hO0}-14 \mathrm{~h} 00$ & Intervalo para o almoço \\
\hline $14 h 00-15 h 30$ & $\begin{array}{l}\text { Apresentação de estudos sobre espaços livres em Maceió } \\
\text { Apresentação do projeto de pesquisa em andamento sobre A pro- } \\
\text { dução dos espaços de uso público na cidade de Maceió na segunda } \\
\text { metade do século XX (Geraldo M. G. Faria, Mep - FAU-UFAL) } \\
\text { Pontos e fluxos: Apropriações no espaço público da cidade de } \\
\text { Maceió (Pollenya R. C. Pontes - Cesmac) } \\
\text { No olho da rua: Dinâmica da arte urbana em Maceió (lvy P. C. } \\
\text { Pessôa, Deha - UFAL) }\end{array}$ \\
\hline
\end{tabular}




\begin{tabular}{|c|c|}
\hline $14 \mathrm{~h} 00-15 \mathrm{~h} 30$ & $\begin{array}{l}\text { As zonas de interesse paisagístico no Plano Diretor de Maceió } \\
\text { (Bianor Monteiro, Deha - FAU-UFAL } \\
\text { Os corredores de atividades múltiplas em Maceió (Viviane R. Costa, } \\
\text { Deha - UFAL) } \\
\text { A violência e os espaços livres (Morgana M. P. D. Cavalcante, Ellen } \\
\text { P. N. Souza, Mep - FAU-UFAL) } \\
\text { A iluminação pública em Maceió (Cláudio Bergamini, Gepa - UFAL) } \\
\text { Os campos de pelada e a dinâmica do sistema de espaços livres } \\
\text { em Maceió (Nelcy M. Santos, Deha - UFAL) } \\
\text { Pesquisa sobre vazios urbanos em Maceió (Regina Lins, Veronica } \\
\text { Robalinho, Nest - UFAL) }\end{array}$ \\
\hline $15 \mathrm{~h} 30-15 \mathrm{~h} 45$ & Debates \\
\hline $15 \mathrm{~h} 45-16 \mathrm{~h} 10$ & Intervalo para o café \\
\hline $16 h 10-16 h 30$ & $\begin{array}{l}\text { Estudos de climatologia urbana e os espaços livres (Gianna M. } \\
\text { Barbirato, Geca - FAU-UFAL }\end{array}$ \\
\hline 16h30 - 16h50 & $\begin{array}{l}\text { Estudos de engenharia ambiental sobre os espaços livres de Maceió } \\
\text { (Vladimir Caramori, Ctec-UFAL) }\end{array}$ \\
\hline $16 h 50-17 h 10$ & $\begin{array}{l}\text { Estudos de geografia urbana sobre os espaços livres de Maceió } \\
\text { (Rochana Santos, Igdema-UFAL) }\end{array}$ \\
\hline $17 h 10-17 h 30$ & $\begin{array}{l}\text { Estudos de antropologia e sociologia urbanas sobre os espaços } \\
\text { livres de Maceió (Bruno C. Cavalcanti-UFAL) }\end{array}$ \\
\hline $17 \mathrm{~h} 30-18 \mathrm{~h} 00$ & Debates \\
\hline
\end{tabular}

(*) Secretaria Municipal de Planejamento, Secretaria Municipal de Controle do Convívio Urbano

\begin{tabular}{l|l}
\hline $\begin{array}{l}\text { 4 de dezembro } \\
\text { terça-feira }\end{array}$ & \multicolumn{1}{c}{ Programa } \\
\hline $8 \mathrm{~h} 30-9 \mathrm{H} 00$ & $\begin{array}{l}\text { Síntese dos trabalhos do 10 dia - Exposição da sistemática dos } \\
\text { trabalhos e constituição dos grupos de trabalho }\end{array}$ \\
\hline 9 h00 - 10h30 & $\begin{array}{l}\text { Oficina sobre o sistema de espaços livres de Maceió (todos os } \\
\text { participantes) }\end{array}$ \\
\hline 10h30 - 10h50 & Intervalo para o café \\
\hline $10 h 50-12 h 00$ & $\begin{array}{l}\text { Oficina sobre o sistema de espaços livres de Maceió (todos os } \\
\text { participantes) }\end{array}$ \\
\hline 12h00 - 14h00 & Intervalo para o almoço \\
\hline $14 h 00-16 h 00$ & $\begin{array}{l}\text { Oficina sobre o sistema de espaços livres de Maceió (Todos os } \\
\text { participantes) }\end{array}$ \\
\hline 16h00 - 16h20 & Intervalo para o café \\
\hline 16h20 - 17h30 & Apresentação dos trabalhos dos grupos - Debates \\
\hline 17h30 - 18h00 & Conclusões e encerramento \\
\hline
\end{tabular}

Apoios: Faculdade de Arquitetura e Urbanismo, mestrado em Dinâmicas do Espaço Habitado (DEHA) 


\section{OFICINA DE TRABALHO EM VITÓRIA-ES}

Dias 19 e 20 de fevereiro de 2008

Local: Auditório do Centro de Artes UFES

Participantes do Núcleo QUAPÁ-SEL São Paulo: Os professores doutores Silvio Soares Macedo e Helena Degreas; arquitetos Fany Galender e Marcos Fernandes C. Rios; e graduando FAUUSP Marco André C. Salles.

\subsubsection{8}

Dia destinado à realização de visitas técnicas às cidades de Vitória, Serra, Vila Velha e Cariacica, possibilitou a observação e registro em imagens dos diferentes tecidos urbanos e das tipologias dos espaços livres urbanos significativos das quatro principais cidades que compõem a região metropolitana de Vitória.

Os percursos foram realizados em circuitos previamente estabelecidos com os parceiros locais, que participaram tanto do sobrevôo como das visitas terrestres.

\subsubsection{8}

Abertura: recepção e apresentação dos convidados e participantes

Professores doutores Eneida Maria de Souza Mendonça (coordenadora do Núcleo QUAPÁ-SEL Vitória - UFES); Cristina Engel (diretora do Centro de Artes UFES); Francisco Guilherme Emmerich (pró-reitor de pesquisa e pós-graduação UFES); Antonio (coordenador de Mestrado - Departamento de Geografia - UFES).

\section{Apresentação 1}

Os sistemas de espaços livres e a constituição da esfera pública contemporânea no Brasil: Um processo de investigação nacional

Prof. Dr. Silvio Soares Macedo - FAUUSP

(coordenador nacional da pesquisa QUAPÁ-SEL)

A apresentação destacou os seguintes aspectos:

1. Apresentação do Projeto Quapá, sua história e seus objetivos

2. Objetivos da pesquisa SEL

3. Estruturação da pesquisa em rede nacional

4. Resultados gerais esperados

5. Procedimentos de trabalho

Foram discutidos os conceitos e objetivos que norteiam a pesquisa, focando na busca por uma definição de sistema e suas bases de constituição (dependência, articulação, conjunto, fatores de eficiência de um sistema, tipos de sistemas, conflitos e etapas de constituição de um sistema); a articulação entre espaço livre público e privado; suas funções: circulação, lazer-recreação, acesso, conservação, preservação, produção. 
Partindo-se do conceito de espaço livre de edificação, proposto por Miranda Magnoli, pode-se contrapor noções de área verde, área aberta, espaço verde, porém enfatizando sempre que a articulação entre espaços livres e edificados configuram e qualificam a forma urbana, organizando seus tecidos diversos. Discutiu-se a distribuição dos espaços livres a partir da acessibilidade e qualificação funcional. Foram discutidos, ainda, outros conceitos relevantes à pesquisa: processo de verticalização urbana, densidade habitacional e de construção, características das situações de demanda por espaços livres, atributos funcionais, estoque de áreas para o sistema em questão. Observou-se também a demanda por conservação, preservação e manutenção de áreas de encostas, bosques e corpos d'água, entre outros, bem como as finalidades ambientais, com a expressão estética que essas configurações espaciais assumem.

\section{Apresentação 2}

\section{Gestão de espaços livres municipais}

\section{Arquiteto Fabrício Sanz Encarnação \\ Gerência de Projetos Urbanísticos (Sedec)/Prefeitura Municipal de Vitória}

Apresentação de três projetos de intervenção em orlas, atualmente em execução: orlas de Nova Palestina, Maria Ortiz e Camburi, destacando, como a gênese da diretriz das intervenções urbanísticas e paisagísticas, a criação do projeto como processo. No caso da orla de Maria Ortiz, constatou-se que se tratava de local de impedimento de permanência, devido à existência de rede de alta tensão. Foi proposta a criação de corpos estriados (locais onde se pode ocupar, com pequenas áreas de estar), calçadões e ciclovias (o usuário circula; não permanece), trabalhando sempre a questão limite/ tensão/margem (no caso, o mangue). $\bigcirc$ projeto da orla de Nova Palestina visa área limite entre o mangue e a área pública, sendo previstas áreas de estar, recreação infantil (banco jacaré, arco-íris, joaninha), nas quais a ênfase está nas referências lúdicas e de temática infantil. A orla de Camburi se situa em área limite entre o natural e o urbano. mar espraiando, assim como a cidade em sentidos contrários, questionando quais são os limites entre o asfalto, a praia e o mar. $\bigcirc$ projeto cria ambientes de estar com bancos, pergolados e quiosques como esculturas arquitetônicas. A exposição dos projetos pautou-se mais na explanação da essência dos projetos, sua poética e menos em seus aspectos técnicos de detalhamento e execução.

\section{Apresentação 3}

\section{Gestão de espaços livres municipais}

\section{Arquiteto Alexandre Fiorotti}

Departamento de Planejamento Urbano (Sedur)/Prefeitura de Serra

palestrante abordou a ocupação do território e a formação do município de Serra, composto a partir dos núcleos de Nova Almeida, Serra-sede e Carapina, em 
um processo de descontinuidade urbana, com muitos vazios urbanos entre eles. $\mathrm{Na}$ década de 1960 ocorreram inúmeros loteamentos de glebas e, com a implantação de Companhia Siderúrgica de Tubarão e a expansão da atuação da Companhia Vale do Rio Doce houve uma intensa demanda para implantação de conjuntos habitacionais para população de baixa renda, via Cohab e Inocoop. Foi lembrado que, devido à legislação de parcelamento do solo então vigente, aqueles ficaram sem área para uso público e implantação de equipamentos sociais. Com a Lei Lehmann, em 1976, houve um decréscimo na aprovação de loteamentos, apesar de ser possível verificar que, no município, mesmo após a lei, permaneceu a prática de ignorar a destinação de áreas para o sistema de espaços livres. Atualmente, com o Plano Diretor do Município em vigência, inicia-se a verticalização de inúmeros bairros como Laranjeiras e a destinação de áreas públicas para conservação e preservação. Verifica-se, concomitantemente, o aumento de loteamentos e condomínios para alto padrão.

\section{Arquiteto Rafael Fontes}

Departamento de Projetos de Obras Públicas (Sedur)/Prefeitura de Serra

Destacou os procedimentos de seleção de demandas de projetos, definição de prioridades e as etapas de viabilização de projeto e obras no município de Serra. $\bigcirc$ município divide suas obras em dois tipos: as obras da cidade, advindas de demanda política ou técnica; e as obras definidas pelo orçamento participativo, com consulta popular, levantamento e planejamento da rede existente. Percebe-se, atualmente, uma alta demanda por quadras poli-esportivas cobertas e de futebol de areia, campos de futebol de areia, quadras de bocha, mesas de jogos, ciclovias e pistas de caminhada, playgrounds, equipamentos de ginástica e praças de eventos. Concluiu sua exposição com a apresentação dos projetos recentes, sobretudo as intervenções em orlas.

\section{Apresentação 4}

\section{Planejamento estratégico dos recursos naturais de Serra}

\section{Bióloga Edmara Lourenção}

Secretaria Municipal de Meio Ambiente (SEMMA)/Departamento de Recursos Naturais do Município de Serra

A palestrante discorreu sobre a configuração da cidade de Serra em função da situação ambiental do território, isto é, de acordo com seus ecossistemas, elementos de drenagem natural e sistema viário. A prioridade atual do departamento é o estabelecimento de critérios para a criação de áreas de preservação a partir de áreas ainda não-loteadas. O município conta, hoje, com cinco unidades de conservação (entre APAs e reservas), estando em definição seus planos de manejo. Apresentou os processos de implantação de outras áreas de preservação e seus planos de manejo (Jardim Botânico de Serra, APA de Praia Mole, APA Municipal do Viajante, Parque Natural Municipal de 
Bicanga, APA da Lagoa de Jacuném, APA Mestre Álvaro) e de outras ações sobre os espaços livres da cidade.

\section{Apresentação 5}

\section{Plano Básico de Urbanização Integrada das Margens do Rio Aribiri}

Arquiteta Lilian Miranda Damasceno

Secretaria Municipal de Desenvolvimento Urbano (SEMDU)/Prefeitura de Vila Velha

Abordou o Plano Básico de Urbanização Integrada das Margens do Rio Aribiri, em andamento graças aos recursos federais do Plano de Aceleração do Crescimento - PAC.

Trata-se de área de baixa renda, carente de infra-estrutura básica, ao lado de uma outra área que já está sendo atendida por outro recurso, e de ocupação consolidada desde a década de 1970. Caracteriza-se por ser área de manguezal aterrada, com a presença de palafitas, com alta degradação das águas do rio.

Verifica-se a existência de fragmentos de mangue ainda existentes e está sendo estudada a implantação de atracadouro, pois o rio ainda é utilizado. Está previsto, no projeto, o tratamento de encostas, reforma de escolas, projeto de macrodrenagem, implantação de parque linear, procurando a acessibilidade com bicicletas.

A recuperação do rio e do mangue tem como objetivo melhorar a relação da população com o rio por meio de calçadas, praças para convívio e arborização adequada. Já o parque proposto tem a intenção de segurar a ocupação irregular contínua, com o remanejamento da população excedente para outras áreas próximas.

\section{Apresentação 6}

\section{Gestão de espaços livres municipais}

Secretaria Municipal de Planejamento e Desenvolvimento Urbano (Semplad)/Prefeitura de Cariacica

Arquiteto João Marcos Charpinel Borges

arquiteto apresentou um histórico do município de Cariacica, destacando seu papel de cidade-dormitório da capital. Com a chegada da Companhia Vale do Rio Doce e da ferrovia, a cidade se expande e, na década de 1960, o desenvolvimento industrial acaba consolidando a cidade como local de moradia. Assim como as demais cidades da região metropolitana de Vitória, os loteamentos irregulares e clandestinos persistem até mesmo depois da instituição da Lei Federal n. 6766/1979. As diretrizes definidas pelo Plano Diretor do Município são: interação das esferas públicas e privadas: conter o avanço da malha urbana sobre a rural (atualmente, não se está aprovando nenhum loteamento) e aplicação do estatuto da cidade; no âmbito da esfera pública: criação de parques, praças e logradouros. 
No Plano de Gestão dos Espaços Livres Públicos serão implantados os seguintes projetos: Parques - morro da Compainha, Cravo e a Rosa e S. Bárbara; Praças - de Cariacica Sede, de Campo Grande, Trevo de Alto Lage; Logradouros - Avenida Expedito Garcia (Projeto Calçada Viva, seguindo o conceito de shopping a céu aberto, visando reordenar a área de comércio de ambulantes), urbanização da orla de Cariacica (em licitação), com a adequação das calçadas nos bairros (pólos comerciais).

\section{Apresentação 7}

\section{Reabilitação de áreas degradadas}

Secretaria de Meio Ambiente de Cariacica

(SEMMAM)/Gestão de Unidades de Conservação

Bióloga Aparecida Demoner Ramos

A palestrante discorreu sobre o programa de criação de mais duas unidades municipais de conservação dos manguezais de Cariacica, que se somarão às quatro já existentes: o Parque Natural Municipal do Itanguá (localizado em solo urbano, com recuperação e restauração de área ocupada por esgoto, considerando o mangue como área verde da cidade) e a Reserva de Desenvolvimento Sustentável Municipal Manguezais de Cariacica (onde foi adotado outro estatuto jurídico para permitir que os 200 catadores de sururu e siri permaneçam no local). $\bigcirc$ objetivo precípuo dessas duas intervenções é a criação de um circuito turístico dos manguezais de Cariacica, gerando renda com o patrimônio natural.

Destacou, ainda, a implantação da Área de Proteção Ambiental Municipal Monte Mochuara e do Parque Natural Municipal do Monte do Mochuara, ambas as áreas abrigando sítios arqueológicos.

\section{Debate}

Prof. Msc. Homero Penteado (DAU-UFES) - Pede que as secretarias se posicionem sobre a questão dos sistemas de espaços livres e questiona a postura dos projetos diante da adequação aos seus locais. Por exemplo: por que as praias não podem ser somente praias e precisam ter ciclovias, estares, etc., gerando problemas ambientais? Por que tudo tem de ser pavimentado e não se pisa no chão?

Profa. Dra. Eneida Mendonça (DAU-UFES e QUAPÁ-SEL Núcleo Vitória) - Expõe que a idéia era cada setor ou secretaria mostrar o que está realizando, quais seus projetos e objetivos.

Arquiteto Ronaldo (Prefeitura de Vitória): Pede esclarecimentos ao Prof. Dr. Silvio Macedo sobre a questão da qualidade com relação à função.

Prof. Dr. Silvio Macedo: Esclarece que todo espaço livre deve ter um atributo para não ser descartável. Deve ser verificada qual é demanda para esse espaço e ser proposta uma gestão para ele. Os espaços devem ter uma função na cidade: não ne- 
cessariamente possuir equipamentos, mas permitir usos diversos, além de fornecer um conforto mínimo para o usuário. Pode ter um papel na drenagem e gerar elementos de identificação do usuário por meio de sua linguagem.

Propõe a questão para a plenária: até que ponto um projeto pensado na hora certa não impede, simplesmente, de correr-se atrás do prejuízo, tornando-o mais caro? Isto é, a ausência de planejamento, de uma reflexão mais aprofundada e abrangente não permitiria acontecer grande parte dos problemas de nossas cidades.

As intervenções realizadas nessa manhã por técnicos de diferentes órgãos e esferas mostrou-nos como as cidades estudadas vêem a questão de seus espaços livres perante a estruturação de cada cidade, seus problemas ambientais e suas demandas por equipamentos e locais de práticas esportivas, recreacionais e de lazer e convívio. A definição, implantação e gestão dos espaços livres urbanos variam para cada caso e mostrou-nos um amplo leque de situações e possibilidades de atuação, sempre lembrando que a atuação conjunta, em equipes multidisciplinares, é imprescindível para abarcar a complexidade do meio urbano.

\title{
Apresentação 8
}

\section{Apresentação dos trabalhos desenvolvidos pelo Núcleo de Arquitetura e Urbanismo da Universidade Federal do Espírito Santo (NAU-UFES) ligados à Pesquisa QUAPÁ-SEL}

\author{
Profa. Dra. Eneida Maria Souza Mendonça \\ Departamento de Arquitetura e Urbanismo UFES
}

Os trabalhos desenvolvidos pelo grupo coordenado pela Profa. Dra. Eneida buscam desenvolver produtos que aprofundem os seguintes itens:

1. Método para análise e construção da paisagem

2. Análise e construção da paisagem

3. Apropriação alternativa do ambiente urbano

Já foram realizadas atividades de caráter empírico, concluídas dentro do escopo da pesquisa, por meio de três bolsas de Iniciação Científica (PIBIC - CNPq), cujos resultados foram apresentados no VIII ENEPEA, em 2006, e no II Colóquio da Pesquisa realizado em São Paulo, em setembro de 2007.

Na seqüência, apresentaram-se as novas pesquisadoras do Núcleo QUAPÁ-SEL Vitória. São elas: Thais Sartori, Análise comparativa das principais tipologias de Vitória (PIBIC - CNPq); Luciana Bandeira de Oliveira, Análise preliminar dos espaços livres na baía Noroeste de Vitória (PIBIC - CNPq); Cynthia L. P. de Miranda, Ocupação em áreas de preservação ambiental: Uma proposta para Vila Velha (bolsista de aperfeiçoamento - Facitec); Caroline Jabour de França, Análise do tecido urbano da cidade de Vitória-ES. A arquiteta está se integrando à pesquisa, após doutorado realizado em Milão sobre o desenho urbano da cidade de Vitória, onde divide a cidade em zonas de tipologias 
de edificação e ocupação em um esforço de compreensão da estruturação do tecido urbano; Doriéli Z. Fornaciari, Espaço físico e espaço virtual: $O$ desafio dos espaços públicos de lazer e cultura na cidade contemporânea e na era da informação - Trabalho final de graduação (TFG) em andamento.

Nesse momento, o objetivo dos trabalhos em desenvolvimento no Núcleo QUAPÁSEL Vitória é dar continuidade às pesquisas anteriores, utilizando material anteriormente produzido, para avaliação do desempenho dos espaços livres e as possibilidades futuras de intervenção e constituição de um sistema eficiente.

\title{
Apresentação 9
}

\section{Metropolização da Grande Vitória: ausência de espaços públicos na constituição da região metropolitana da Grande Vitória}

\author{
Profa. Dra. Ana Lucy Oliveira Freire
}

Departamento de Geografia - UFES

Trabalhando na escala metropolitana, parte da idéia de urbanização e desigualdade do crescimento dos diversos municípios da metrópole capixaba. Aborda a idéia de núcleo e periferia, por meio de um quadro da urbanização brasileira e suas 27 regiões metropolitanas. A pesquisadora se pergunta quais os parâmetros e finalidades desse processo, apresentando alguns pressupostos de sua pesquisa. Destaca a modernização do estado e os novos investimentos públicos e privados no Espírito Santo, que, até 30 anos atrás, tinha sua riqueza assentada na economia cafeeira. Enfatiza a estrutura viária e o aumento de mobilidade geral decorrente de novas vias e terminais rodoviários. Aponta algumas figuras novas que surgem na paisagem urbana capixaba, típicas da cidade brasileira contemporânea, na qual a fragmentação e a segregação são preponderantes.

\section{Apresentação 10}

\section{Corredores verdes em Vitória}

Prof. Msc. Homero Penteado

Departamento de Arquitetura e Urbanismo - UFES

Utiliza os conceitos de Formann, de corredor, matriz e fragmento e associa-os com a idéia da cidade como matriz urbana. A apresentação se assenta em fundamentos consolidados no paisagismo e na ecologia da paisagem. Mostra um bom mapa analítico de um setor urbano da capital e aplica os conceitos em uma área vizinha ao campus da UFES, na qual foca seu estudo de caso. Por meio de trabalhos de campo realizados com os alunos da graduação no bairro Jardim da Penha, com suas ruas largas e pequenas calçadas, apresenta uma competente análise da situação atual e das potencialidades do local, à luz da teoria adotada. 


\title{
Apresentação 11
}

\section{Caracterização do patrimônio ambiental em Cariacica e Serra para elaboração de planos diretores municipais}

\author{
Prof. Dr. André Luiz Nascentes Coelho - Consultor em meio ambiente e \\ geoprocessamento \\ Fundação Ceciliano Abel de Almeida (FCAA - UFES) - Núcleo Cidades
}

trabalho busca desenvolver uma metodologia que identifique os recursos e ferramentas para a elaboração de PDM, visando à indicação das áreas de interesse ambiental. Parte da junção de uma série de informações para uma análise de multicritérios, indicando potencialidades e limites do território e classifica as áreas do ponto de vista ambiental para a geração de diretrizes e legislação. Tendo por base as legislações existentes, são realizadas, simultaneamente, a análise dos atributos e um comentário sobre cada área. São estabelecidas diretrizes para o município e realizada uma apresentação em audiência pública, após a qual é feita uma reavaliação. Para a cidade de Serra, por exemplo, foram elaborados mapas de análise do relevo, declividades, precipitação e temperaturas médias anuais, rede hidrográfica e drenagem, mostrando o conhecimento do território. A partir de uma pré-seleção de locais para os trabalhos de campo com GPS e registro fotográfico foram determinados atributos como características da flora, recursos hídricos, valor cênico, fragilidade, e realizada a identificação das áreas de interesse ambiental, com comentários sobre as características da área.

\section{Apresentação 12}

\section{Aplicações da caracterização do patrimônio ambiental na elaboração de plano diretor municipal}

\author{
Arquiteto Msc. Giovanilton André Ferreira \\ FCCA-UFES - Instituto Cidades
}

Membro do Instituto Cidades, que tem elaborado planos diretores municipais para diversas cidades do estado com equipe multidisciplinar, o pesquisador expôs a metodologia de elaboração desses planos. $\bigcirc$ método parte de três leituras: a técnica (patrimônio ambiental, arquitetônico, mobilidade e acessibilidade), a dos governantes (política) e a da população (demandas locais). Considera como estrutura básica dos planos diretores a definição de eixos prioritários, perímetro urbano, macrozoneamento, zoneamento, índices urbanísticos e conflitos ambientais e de caráter socioeconômico. $\bigcirc$ resultado final aparece sempre como um processo de negociação permanente. 


\title{
Apresentação 13
}

\section{Dinâmica urbana da região metropolitana da Grande Vitória (RMGV) na década de 1990}

\section{Arquiteto Jose Carlos da Silva Oliveira}

Instituto Jones dos Santos Neves (IJSN) - Governo de estado do Espírito Santo

Foram apresentados dois trabalhos, sendo o primeiro gerado a partir de um vôo no final da década de 1990, que resultou no documento Dinâmica urbana na década de 90, o que permitiu a comparação com material do final da década anterior e a detecção da evolução do crescimento urbano da RMGV. O segundo estudo analisa o processo de verticalização do espaço urbano. É apresentado um quadro da conformação do território pré-metropolitano que destaca a implantação das grandes plantas industriais e portuárias e os grandes conjuntos habitacionais nos anos 1960-1970, sobretudo em Vitória e Vila Velha. $O$ vetor de adensamento e as zonas de adensamento urbano são caracterizados. A RMGV, de 1980 a 1990, caracteriza-se pelo predomínio do adensamento dos novos parcelamentos, a ocupação de grandes áreas por instalações de abrangência metropolitana (shopping centers, hospitais, universidades, porto), o elevado índice de verticalização localizada e a consolidação de novas territorialidades metropolitanas. De 1960 a 1980, os parcelamentos ocorreram sem nenhuma preocupação com o espaço livre: os grandes espaços foram ocupados pelas instituições e, os espaços privados, loteados. Identifica-se, na paisagem urbana da metrópole, a consolidação de um eixo de verticalização do sul de Vila Velha ao norte de Vitória, expandido na década 1990-2000 com a inclusão de Guarapari. $\bigcirc$ pesquisador questiona quais serão as futuras territorialidades; qual será a dinâmica urbana para 2010; qual será a dinâmica dos espaços livres públicos diante dessa tradição. Sugere a estratégia de implantação de condomínios de baixa densidade com a intenção de criar espaços livres públicos.

\section{Apresentação 14}

\section{Gestão das Unidades de Conservação do Estado do Espírito Santo}

\author{
Aline Alvarenga - Analista de Meio Ambiente e Recursos Hídricos - \\ Gerência de Recursos Naturais \\ Instituto Estadual de Meio Ambiente e Recursos Hídricos (IEMA) - \\ Governo do estado do Espírito Santo
}

A analista de meio ambiente apresentou mapas com um histórico dos biomas do Espírito Santo que, por sua vez, está totalmente inserido na Mata Atlântica. Atualmente, somente restam $8 \%$ de área desse ecossistema, estando ocupada em $40 \%$ por pastagens, $26 \%$ por outros usos e 19,32\% pela lavoura. Apenas 2,5\% estão sob a denominação de unidades de conservação: 1,5\% em âmbito federal, 0,98\% em âmbito estadual e 0,06\% em âmbito municipal. $\bigcirc$ Instituto trabalha com a definição de unidades de conservação, 
conforme o SNUC, Lei n. 9.985/2000, e possui 16 unidades de conservação no estado sob seu gerenciamento, com diferentes denominações e estatutos jurídicos, tais como: Área de Proteção Ambiental, Área de Relevante Interesse Ecológico, Monumento Natural, Parque Estadual, Reserva Ecológica, Reserva de Desenvolvimento Sustentável. Tratou da criação e implementação dessas unidades, que se originam a partir de consulta pública e do processo de definição dos objetivos de manejo, delimitação, instrumento legal, órgão gestor-conselho e plano de manejo, destacando a situação ambiental atual da região metropolitana de Vitória. A explanação foi extremamente rica, pois trabalhou com as definições da legislação, confrontando-a com situações concretas do território em estudo pelo grupo.

\subsubsection{8}

Como não foi possível contar com a presença de representantes dos movimentos populares no dia previsto, antes do início das atividades de discussão e elaboração do produto final da oficina, ouvimos as falas de dois convidados desse setor que, posteriormente, incorporaram-se às equipes de trabalho.

\section{Apresentação 15}

\section{Movimentos populares - Conselho Popular de Vitória (CPV)}

\section{Senhor Waldemar Cunha}

A cidade é gestada por conselhos, não-deliberativos, mas constantemente chamados para respaldar as decisões políticas. Essa situação leva à reivindicação de maior participação (inclusive a paridade), apesar de seus membros não terem formação técnica, contribuindo, no entanto, com o olhar da população, do usuário. Na atual administração, houve o regate do orçamento participativo, permitindo maior participação da população, manifestando seus próprios interesses e demandas, variáveis de localidade para localidade. Lembrou ainda que nos bairros melhores, a população não quer que determinadas construções ou ações venham a ser implementadas, pois acredita que acarretará o estabelecimento de uma outra comunidade indesejada. $\bigcirc$ movimento quer evitar a visão pontual, procurando uma visão mais coletiva, menos voltada para um único grupo, mas contemplando o atendimento de um maior número de pessoas, o coletivo e a inclusão. Propõe um olhar multidisciplinar que tente ser o mais abrangente possível, com a idéia do cidadão como um agente de transformação. A grande preocupação do movimento é a maneira com que os novos empreendimentos estão sendo implantados, levando em consideração o futuro, especialmente quanto à mobilidade, acessibilidade e visibilidade. 


\section{Apresentação 16}

\section{Movimentos populares - Conselho Comunitário de Vila Velha (CCVV)}

\section{Advogado Sandro Ghuio Franzotti}

Expôe que a falta de planejamento e sua defasagem na demora da implantação é o grande problema de nossas cidades. $\bigcirc$ conselho vem analisando seus problemas, tendo em vista o intenso crescimento da cidade e sua disparidade social acentuada. Discorreu sobre a forma de abordagem de problemas enfrentados, a participação do conselho e os descaminhos da elaboração e implementação do Plano Diretor de Vila Velha, diante da pressão política e os conflitos de interesses. Destacou também a ausência de uma visão de longo prazo nas ações públicas, o que certamente irá comprometer qualquer proposta de uma cidade saudável.

\section{CONSIDERAÇÕES SOBRE AS APRESENTAÇÕES}

painel de apresentações permitiu aos participantes uma reflexão acerca das metodologias de abordagem, prioridades de enfoque, dificuldades na consecução de objetivos, conflitos entre distintas esferas de atuação do poder público, pressões dos diferentes agentes que atuam na construção do espaço livre urbano, entre outras questões, somando informações para a etapa seguinte, de estabelecimento de diretrizes gerais de atuação sobre os espaços livres urbanos da região metropolitana da Grande Vitória.

Ressaltamos a presença de membros da Fundação Vale do Rio Doce que se resumiram à condição de ouvintes nas exposições de trabalhos do dia 20 de fevereiro de 2008 e de sua participação em um dos grupos de trabalho. Ressaltamos também a marcante ausência de representantes da Petrobrás e do mercado imobiliário, cujas presenças poderiam ter propiciado um confronto positivo de posturas e o conhecimento mais aprofundado das diferenças entre grupos de interesses diversos.

\section{A oficina}

Cada oficina tem sua especificidade devido às distintas realidades e às diferentes informações que cada participante aporta. No caso de Vitória, o diferencial se deu graças à participação de membros de outras três cidades as quais integram a região metropolitana: Vila Velha, Cariacica e Serra.

Contando com 17 participantes, foram formados quatro grupos com profissionais de formação heterogênea e de diferentes instituições. Devido ao predomínio de participantes de Vitória, os técnicos dos demais municípios acabaram por assessorar todas as equipes, além de atuarem em seus próprios grupos, o que contribuiu para o aprofundamento das análises. 
A oficina teve como objetivo a discussão do sistema de espaços livres da região e iniciou-se com a formação de quatro grupos, conforme a temática abaixo:

- Sistema de parques, calçadões de praia e praças, áreas de conservação e preservação ambiental (cinco participantes);

- sistema de espaços livres privados e tecidos urbanos (quatro participantes);

- investimentos públicos, plano diretor e crescimento urbano x metropolização (cinco participantes);

- legislação e mercado imobiliário (três participantes).

Cada grupo discutiu uma temática específica para, posteriormente, confrontar com as outras temáticas, criando mapas que apresentassem:

a) espacialização de características de cada local (como é a paisagem daquele lugar); b) exposição de conflitos; c) apresentação de potencialidades.

Após a manifestação de cada equipe e a discussão das abordagens, foram elaborados mapas-síntese, atualmente em processo de finalização pelo QUAPÁ-SEL Núcleo Vitória, possibilitando pareceres e eventuais complementações de todos os demais participantes do evento. 


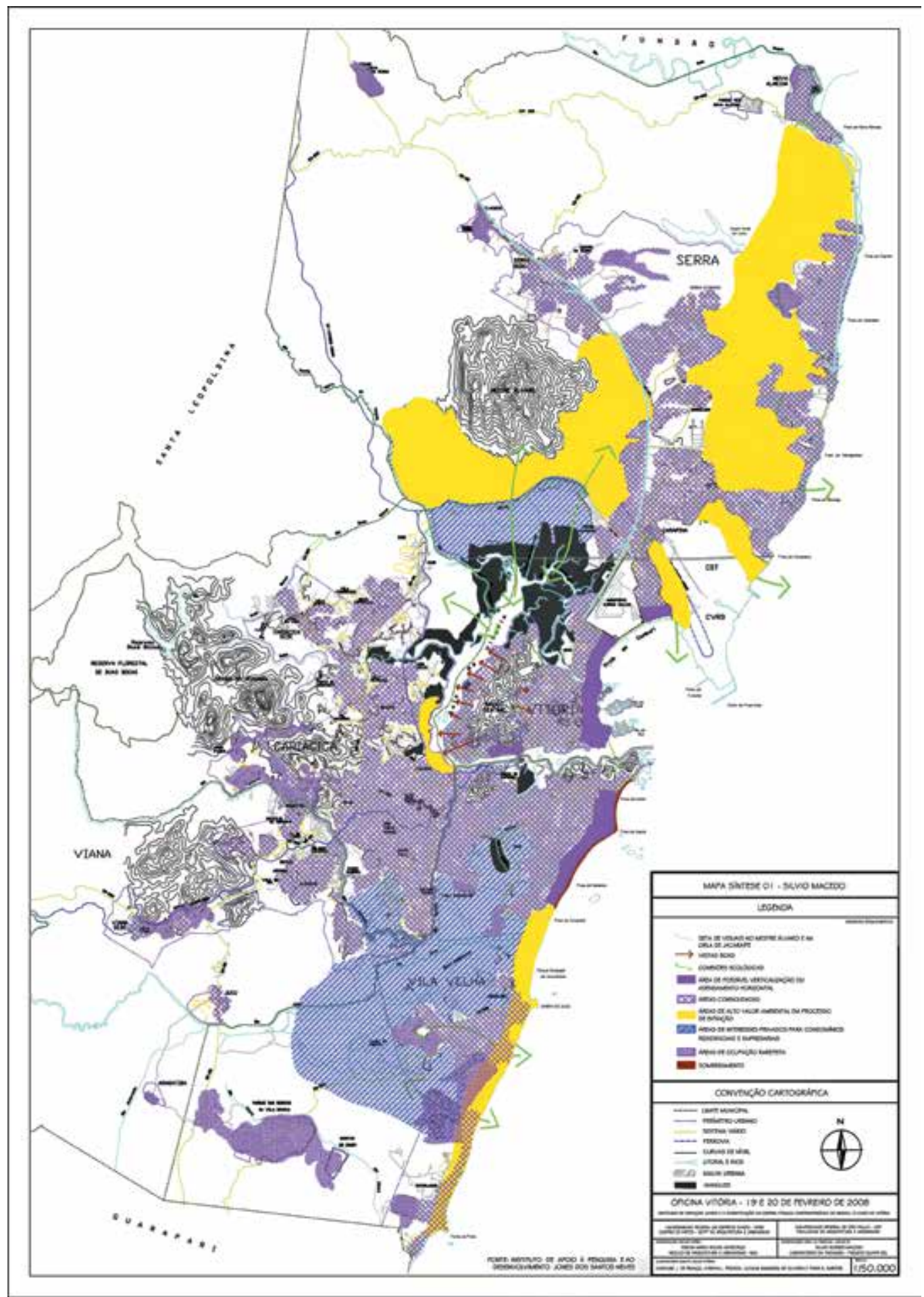

Mapa-síntese da oficina de Vitória

Crédito: QUAPÀ-SEL Núcleo Vitória 


\section{Pesquisa QUAPÀ-SEL \\ Sistema de Espaços Livres Urbanos e Constituição da Esfera Pública Contemporânea no Brasil}

Oficina Vitória

19 de Fevereiro de 2008- $8 \mathrm{~h}: 30$

Auditório do Centro de Artes-Cemuni IV / UFES

Entradafranca

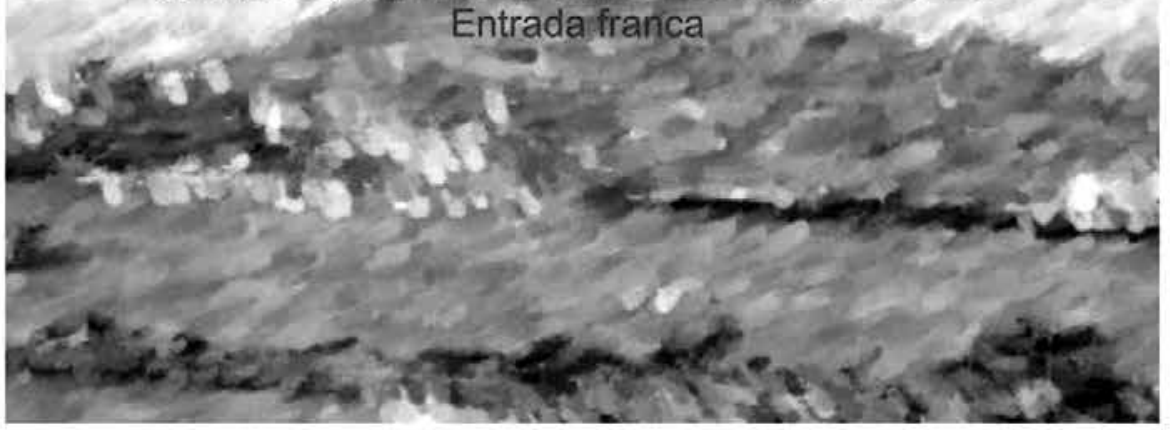

Realização:

Núcleo de Arquitetura e Urbanismo - NAU / UFES

Laboratório da Paisagem - Projeto QUAPÁ/ USP
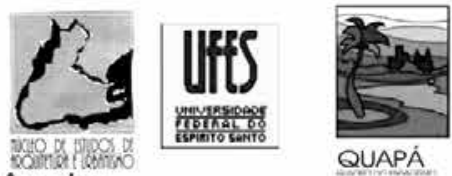

FAUUSP

Apoio:

Programa de Pós-Graduação em Arquitetura e Urbanismo / UFES

Programa de Pós-Graduação em Geografia / UFES

Pró-Reitoria de Pesquisa da USP

\section{园CNPq \\ D JAPESP}
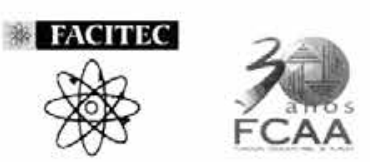

Instituto

CIDADES 
PESQUISA QUAPÁ-SEL

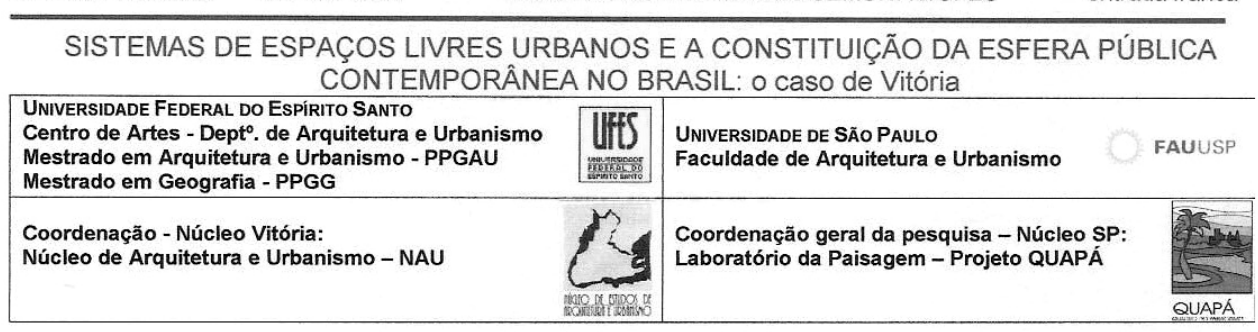

\begin{tabular}{|c|c|}
\hline 19/02 - Ter & Programaçāo \\
\hline $08 \mathrm{~h} 30-9 \mathrm{~h} 00$ & - Abertura / Apresentação dos participantes e convidados \\
\hline $9 h 00-10 h 00$ & - Apresentação da pesquisa QUAPA-SEL - núcleo coordenador nacional \\
\hline $10 \mathrm{~h} 00-10 \mathrm{~h} 15$ & - Gestão dos espaços livres Municipais: Prefeitura Municipal de Vitória - SEDEC \\
\hline $10 \mathrm{~h} 15-10 \mathrm{~h} 30$ & - Gestão dos espaços livres Municipais: Prefeitura Municipal de Vitória - SEMMAM \\
\hline $10 h 30-10 h 45$ & - Gestão dos espaços livres Municipais: Prefeitura Municipal da Serra - SEDUR \\
\hline $10 \mathrm{~h} 45-11 \mathrm{~h} 00$ & - Gestão dos espaços livres Municipais: Prefeitura Municipal da Serra - SEMMA \\
\hline $11 \mathrm{~h} 00-11 \mathrm{~h} 15$ & - Gestão dos espaços livres Municipais: Prefeitura Municipal de Vila Velha - SEMDU. \\
\hline $11 \mathrm{~h} 15-11 \mathrm{~h} 30$ & - Gestão dos espaços livres Municipais: Prefeitura Municipal de Vila Velha - SEMMA \\
\hline $11 \mathrm{~h} 30-11 \mathrm{~h} 45$ & - Gestão dos espaços livres Municipais: Prefeitura Municipal de Cariacica - SEMPLAD \\
\hline $11 \mathrm{~h} 45-12 \mathrm{~h} 00$ & - Gestão dos espaccos livres Municipais: Prefeitura Municipal de Cariacica - SEMMAM \\
\hline $12 \mathrm{~h} 00-12 \mathrm{~h} 30$ & Debates \\
\hline $12 \mathrm{~h} 30-14 \mathrm{~h} 00$ & Intervalo para o almoço \\
\hline $14 \mathrm{~h} 00-14 \mathrm{~h} 15$ & $\begin{array}{l}\text { - Sistema de espaços livres de Vitória - antecedentes e estágio atual da pesquisa (Profa. Dra. } \\
\text { Eneida Maria Souza Mendonça - NAU/UFES) }\end{array}$ \\
\hline $14 h 15-14 h 30$ & $\begin{array}{l}\text { - Análise preliminar dos Espaços Livres da Baía Noroeste de Vitória quanto à localização } \\
\text { (Luciana Bandeira PIBIC/FACITEC-NAU/UFES) } \\
\text { - Análise comparativa das principais tipologias dos espaços livres públicos da região de Vitória - } \\
\text { uma abordagem preliminar (Thais Gonçalves Sartori PIBIC/CNPq-NAU/UFES }\end{array}$ \\
\hline $14 \mathrm{~h} 30-14 \mathrm{~h} 45$ & $\begin{array}{l}\text { - Análise do tecido urbano da cidade de Vitória - ES (Dra Planejamento Urbano Caroline Jabour } \\
\text { de França) }\end{array}$ \\
\hline $14 \mathrm{~h} 45-15 \mathrm{~h} 00$ & $\begin{array}{l}\text { - Ocupação em Áreas de Preservação Ambiental: Uma proposta de Vila Velha (Cynthia L. P. de } \\
\text { Miranda - NAU/UFES / bolsista de aperfeiçoamento FACITEC/Mestrado Arquitetura e } \\
\text { Urbanismo UFES) }\end{array}$ \\
\hline $15 h 00-15 h 15$ & $\begin{array}{l}\text { - Espaços físicos e espaços virtuais: o desafio dos espaços públicos de lazer e cultura na cidade } \\
\text { contemporânea e na era da informação (Doriéli Z. Fornaciari - NAU/UFES) }\end{array}$ \\
\hline $15 h 15-15 h 30$ & $\begin{array}{l}\text { - Caracterização do patrimônio ambiental em Cariacica e Serra para elaboração de Planos } \\
\text { Diretores Municipais (Profo. Dr. André Luiz Nascentes Coelho - FCAA) }\end{array}$ \\
\hline $15 h 30-15 h 45$ & $\begin{array}{l}\text { - Aplicações da caracterização do patrimônio ambiental na elaboração de Planos Diretores } \\
\text { Municipais (Msc. Giovanilton André Ferreira - FCAA Instituto Cidades) }\end{array}$ \\
\hline $15 h 45-16 h 00$ & $\begin{array}{l}\text { - Metropolização da Grande Vitória: Ausência de Espaços Públicos na Constituição da RMGV } \\
\text { (Profa. Dra. Ana Lucy Oliveira Freire-Geografia/UFES) }\end{array}$ \\
\hline $16 \mathrm{~h} 00-16 \mathrm{~h} 15$ & - Corredores verdes em Vitória (Prof. MSC. Homero Penteado - DAU/UFES) \\
\hline $16 \mathrm{~h} 15-16 \mathrm{~h} 30$ & Intervalo para o lanche \\
\hline $16 \mathrm{~h} 30-16 \mathrm{~h} 45$ & - Dinâmica urbana da Grande Vitória - Instituto Jones dos Santos Neves \\
\hline $16 \mathrm{~h} 45-17 \mathrm{~h} 00$ & - Gestão das Unidades de Conservaçäo Estaduais na Grande Vitória - IEMA \\
\hline $17 \mathrm{~h} 00-17: 30$ & Debates \\
\hline \multicolumn{2}{|l|}{ 20/02 - Qua } \\
\hline $8 \mathrm{~h} 30-9 \mathrm{~h} 30$ & Movimentos populares/Conselhos: CPV, FAMES, FAMOC e CCVV \\
\hline $09 h 30-10 h 00$ & $\begin{array}{l}\text { - Síntese dos trabalhos do dia anterior / Exposição da sistemática dos trabalhos e constituição dos grupos } \\
\text { de trabalho }\end{array}$ \\
\hline $10 \mathrm{~h} 00-12 \mathrm{~h} 00$ & - Oficina sobre o Sistema de Espaços Livres de Vitória (com todos os participantes) \\
\hline $12 \mathrm{~h} 00-14 \mathrm{~h} 00$ & Intervalo para o almoço \\
\hline $14 \mathrm{~h} 00-16 \mathrm{~h} 00$ & - Oficina sobre o Sistema de Espaços Livres de Vitória (com todos os participantes) \\
\hline $16 \mathrm{~h} 00-16 \mathrm{~h} 20$ & Intervalo para o lanche \\
\hline $16 \mathrm{~h} 20-17 \mathrm{~h} 30$ & - Apresentação dos trabalhos dos grupos - Debates \\
\hline $17 \mathrm{~h} 30-18 \mathrm{~h} 00$ & Conclusöes e encerramento \\
\hline
\end{tabular}

Apoio:

Instituto 3 FACINEC




\section{Bibliografia}

BARTALINI, Vladimir; LIMA, Catharina Pinheiro Cordeiro dos Santos. Sistema de espaços livres e áreas verdes. Texto de pesquisa. São Paulo: FAUUSP, 2007.

CAVALHEIRO, Felisberto; NUCCI, J. C. Espaços livres e qualidade de vida. São Paulo: FAUUSP, 1977.

COELHO, Leonardo Loyolla. Compensação ambiental: Uma alternativa para a viabilização de espaços livres para convívio e lazer na cidade de São Paulo. 2008. Dissertação (Mestrado) - Faculdade de Arquitetura e Urbanismo, Universidade de São Paulo, São Paulo, 2008.

MACEDO, Silvio Soares et al. Projeto QUAPÁ-SEL. Relatório de Pesquisa. São Paulo: FAUUSP, 2008.

MAGNOLI, Miranda M. Espaços livres e urbanização: Uma introdução a aspectos da paisagem metropolitana. 1982. Tese (Livre-docência) - Faculdade de Arquitetura e Urbanismo, Universidade de São Paulo, São Paulo, 1982.

2006. Parque no desenho urbano. Paisagem e Ambiente: Ensaios, São Paulo: FAUUSP, n. 22, p. 201-203,

MACEDO, Silvio Soares; ROBBA, Fábio. Praças brasileiras. São Paulo: Edusp/Imesp, 2002.

O sistema público de espaços livres e o parque contemporâneo brasileiro. In: PEREIRA, Tânia Sampaio; DA COSTA, Maria Lucia Moreira Nova; JACKSON, Peter Wyse. Recuperando o verde para as cidades: A experiência dos jardins botânicos brasileiros. Rio de Janeiro: Rede Brasileira de Jardins Botânicos - Instituto de Pesquisa Jardim Botânico do Rio de Janeiro. 2007. 103 f. Dissertação (Mestrado em Arquitetura e Urbanismo) - Faculdade de Arquitetura e Urbanismo, Universidade de São Paulo, São Paulo, 2008.

PEREIRA, Raul Isidoro. O sentido da paisagem e a paisagem consentida: Projetos participativos na produção do espaço livre público. 2006. Tese (Doutorado) - Faculdade de Arquitetura e Urbanismo, Universidade de São Paulo, São Paulo, 2006.

FREIRE, Oneida Divina da Silva (Coord.). Projeto Orla: Fundamentos para gestão integrada. Brasília: Ministério do Meio Ambiente/Ministério do Planejamento, Orçamento e Gestão, 2002.

QUEIROGA, Eugenio Fernandes. A megalópole e a praça: $\bigcirc$ espaço entre a razão de dominação e a ação comunicativa. 2001. 351 p. Tese (Doutorado) - Faculdade de Arquitetura e Urbanismo, Universidade de São Paulo, São Paulo, 2001.

ROBBA, Fábio. A praça contemporânea nas grandes capitais brasileiras (1990 a 2004): Do programa à forma projetual. 2004. 267 f. Tese (Doutorado em Arquitetura e Urbanismo) - Faculdade de Arquitetura e Urbanismo, Universidade de São Paulo, São Paulo, 2004.

SAKATA, Francine Gramacho. O projeto paisagístico como instrumento de requalificação urbana. 2004. 135 f. Dissertação (Mestrado em Arquitetura e Urbanismo) - Faculdade de Arquitetura e Urbanismo, Universidade de São Paulo, São Paulo, 2004.

SERPA, Ângelo. O espaço público na cidade contemporânea. São Paulo: Contexto, s. d.

WEINGARTNER, Gutemberg. A construção de um sistema - Os espaços livres públicos de recreação e de conservação em Campo Grande, MS. 2008. 196 p. Tese (Doutorado em Arquitetura e Urbanismo) - Faculdade de Arquitetura e Urbanismo, Universidade de São Paulo, São Paulo, 2008. 